PROF. IVAN DARBY (Orcid ID : 0000-0002-6457-5327)

Article type $\quad$ : Original Research

\title{
Alveolar ridge preservation and early implant placement at maxillary central incisor sites: a prospective case series study
}

Stephen T. Chen, BDS, MDSc, PhD, FRACDS 1

Ivan Darby, BDS, PhD, FRACDS (Perio) ${ }^{2}$

${ }^{1}$ Clinical Associate Professor, Periodontics, Melbourne Dental School, The University of Melbourne, Parkville, VIC, Australia

2Professor, Periodontics, Melbourne Dental School, The University of Melbourne, Parkville, VIC, Australia

Correspondence to:

Dr Stephen Chen, 223 Whitehorse Road, Balwyn, VIC 3013, Australia. Email: schen@periomelbourne.com.au

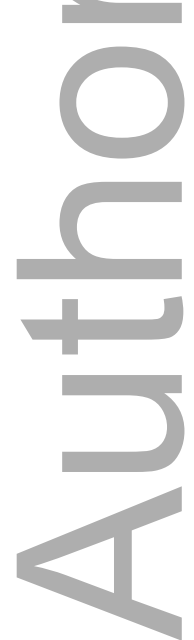

This is the author manuscript accepted for publication and has undergone full peer review but has not been through the copyediting, typesetting, pagination and proofreading process, which may lead to differences between this version and the Version of Record. Please cite this article as doi: 10.1111/CLR.13619

This article is protected by copyright. All rights reserved 


\section{Abstract}

Purpose: To assess whether alveolar ridge preservation (ARP) with $90 \%$ deproteinized bovine bone mineral in a 10\% collagen matrix (DBBMC) and resorbable type I/III porcine collagen matrix (CM) maintains sufficient bone volume for early implant placement 8 to 10 weeks after extraction of maxillary central incisors.

Materials and Methods: In this case series study of 10 consecutively enrolled patients, sockets of maxillary single central incisors requiring extraction and early implant placement were grafted with DBBMC/CM. Ridge dimensions were measured pre-extraction and just prior to implant placement.

Results: ARP maintained sufficient bone volume for implants to be placed in all sites. Compared to pre-extraction, there was a significant reduction in the orofacial dimensions of the ridge $(1.4 \pm 1.07 \mathrm{~mm} ; 13.2 \%$ reduction $)$ and the bone $(0.7 \pm 0.67$ $\mathrm{mm} ; 9.3 \%)$ at the coronal mid-facial region. A significant reduction in apicocoronal height of the crestal bone at midfacial $(1.2 \pm 0.78 \mathrm{~mm})$ and palatal aspects was observed. On CBCT, a statistically significant reduction in alveolar ridge area occurred (10.9 $\pm 13.42 \mathrm{~mm}^{2} ; 12.2 \%$ reduction).

To optimize aesthetic outcomes, 9/10 sites required additional low volume grafting at the coronal region, whereas 1 site required more extensive grating due to a facial bone dehiscence. At 1-year, the implant survival rate was $100 \%$ and median Pink Esthetic Score (PES) was 10 (range 9 -13).

Conclusions: The novel approach of ARP using DBBMC/CM maintains sufficient bone volume for early implant placement $8.9 \pm 0.97$ weeks later, with a $100 \%$ survival rate one year after restoration.

Keywords: Extraction, alveolar ridge preservation, bone graft, wound healing, dehiscence defect, early implant placement, cone beam CT (Abstract word count: 249 words)

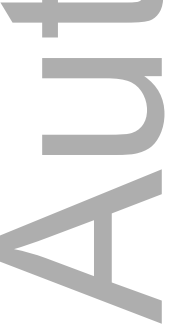

This article is protected by copyright. All rights reserved 


\section{Introduction}

When a tooth is extracted, resorption of the alveolar bone leads to a reduction in the dimensions of the ridge. Studies have demonstrated that the resorption occurs rapidly, with a reduction in more than $50 \%$ of the orofacial ridge dimension after a 12 month healing period (Covani, Cornelini, Calvo, Tonelli, \& Barone, 2010; Schropp, Wenzel, Kostopolous, \& Karring, 2003) due mainly to the resorption of the facial socket wall (Araujo \& Lindhe, 2005; Araujo, Sukekava, Wennstrom, \& Lindhe, 2005). Resorption of the facial socket wall not only results in an apical and palatal displacement of the facial bone crest, but is also characterized by the presence of dehiscence defect in the facial bone in the majority of sites (Chen \& Darby, 2017; Farmer \& Darby, 2014). The dimensional change, reduction in bone volume and formation of dehiscence defects in the facial bone may adversely affect the subsequent placement of dental implants (Seibert \& Salama, 1996). To mitigate the consequences of post-extraction resorption, grafting of extraction sockets for alveolar ridge preservation (ALP) has gained increasing attention over the last 10 years. ARP is defined as a procedure that takes place at the time of extraction, or soon thereafter, with the aim of minimising resorption of the ridge and maximising bone formation within the socket (Darby, Chen, \& De Poi, 2008). A number of systematic reviews have concluded that ARP procedures are successful at reducing the extent of ridge resorption when compared to extraction sockets that are allowed to heal without intervention (Bassir, Alhareky, Wangsrimongkol, Jia, \& Karimbux, 2018; MacBeth, Trullenque-Eriksson, Donos, \& Mardas, 2017; Mardas, TrullenqueEriksson, MacBeth, Petrie, \& Donos, 2015; Morjaria, Wilson, \& Palmer, 2012; Vignoletti et al., 2012). Furthermore, ARP maintains sufficient bone volume to permit implants to be subsequently placed (Darby, Chen, \& Buser, 2009) with ARP sites requiring less additional bone augmentation at the time of implant placement compared to sockets allowed to heal without intervention (Mardas, Chadha, \& Donos, 2010). There is, however, a relative lack of data regarding the efficacy of ridge preservation at sites where aesthetics outcomes are important. In a recent systematic review, 11 randomised controlled trials, controlled clinical trials and case series studies were identified that provided data on ridge preservation in single rooted tooth and premolar extraction sites (Brandam, Malmstrom, Javed, CalvoGuirado, \& Romanos, 2015). The included studies were heterogeneous in the distribution of teeth, and included incisors, canines and premolars in both arches. The merging of data from different tooth sites makes it difficult to evaluate the 
outcome of ARP at individual tooth types (Araujo, da Silva, de Mendonca, \& Lindhe, 2014).

The majority of ARP studies have allowed for post-grafting healing periods of 4 to 6 months before placing implants (Cosyn, Cleymaet, \& De Bruyn, 2016; Eghbali et al., 2018; Koutouzis \& Lipton, 2016; Roccuzzo, Gaudioso, Bunino, \& Dalmasso, 2014; Scheyer et al., 2016). In contrast, the time periods for immediate (type1) and early (type 2) placement protocols are at the time of extraction or 6 to 8 weeks after extraction respectively (Hämmerle, Chen, \& Wilson, 2004). The extended treatment time for ARP may be seen to be a disadvantage and less attractive to patients, particularly when managing replacement of teeth in the aesthetic zone. A recent preclinical study, however, provided histological evidence that implants may successfully osseointegrate when placed 4 weeks after socket grafting (Thoma et al., 2017). This suggests that the earlier placement of implants into ARP sites may be feasible, and if so, would offer a similar duration of treatment to the early (type 2) placement approach. However, there has been little research undertaken with a novel approach of implant placement at an early time frame following tooth extraction and ARP. Therefore, the aim of this single group case series study was to prospectively analyse a consecutive group of patients who underwent ARP following extraction of single tooth maxillary central incisors, followed by the early placement of implants 8 to 10 weeks later. The primary outcome of interest was whether ARP maintained sufficient bone volume to allow implants to be subsequently placed at this time point. The secondary outcomes of interest were the clinical and CBCT dimensional alterations, and to determine if additional grafting was required.

\section{Materials and Methods}

\section{Inclusion and exclusion criteria}

Ethics approval for this study was granted by the University of Melbourne (Ethics ID 1750735) and was performed in accordance with the principles established in the Declaration of Helsinki.

The study was performed in a private practice setting by an experienced clinician (SC). Ten patients who required extraction of a single maxillary central incisor tooth and subsequent implant placement were consecutively enrolled according to the following inclusion criteria:

- Single maxillary central incisors adjacent to natural teeth.

- Dental implants were planned for replacement of the teeth. 
- Periodontal probing pockets $<4 \mathrm{~mm}$.

- Intact facial bone wall determined by pre-extraction cone beam computed tomographic (CBCT) examination (FOV 40 x 40, $80 \mathrm{kV}$ and $6 \mathrm{~mA}$; Morita Veraviewepocs R100; Kyoto, Japan)

- Confirmation of intact socket walls immediately following tooth extraction.

- Adjacent natural teeth were periodontally sound with no periodontal attachment loss.

- Adjacent teeth with healthy dental pulps, or if non-vital, had a satisfactory endodontic status and were free of symptoms.

Patients were excluded if they smoked cigarettes.

\section{Clinical procedures}

The periodontal phenotype was classified as thin, medium or thick by measuring the vertical height of the keratinized gingiva (thin: $\leq 3 \mathrm{~mm}$, medium: 4 to $5 \mathrm{~mm}$, thick: $\geq 6$ $\mathrm{mm}$ ) at the mid-facial aspect of the tooth (Muller, Heinecke, Schaller, \& Eger, 2000). Prior to extraction, removable templates consisting of a stainless-steel wire positioned at the incisal edges of adjacent teeth and embedded in acrylic resin were constructed.

A mesiodistal (MD) reference line orthogonal to the apico-coronal axis of the central incisors was established $5 \mathrm{~mm}$ from the mid-facial and mid palatal gingival margins of the tooth to be extracted (fig 1). The distance of the MD reference line to an acrylic template was recorded. Following administration of local anesthesia ( $2 \%$ lignocaine hydrochloride; 1:100,000 adrenaline), the following were recorded:

- At the MD reference line, the external orofacial dimensions of the ridge at the surface of the mucosa at the mesial, midfacial and distal of the tooth to be extracted was recorded to the nearest millimeter with a surgical caliper (Salvin Ridge Mapping Caliper, Salvin, USA).

- At the same 3 positions, the orofacial dimensions of the alveolar bone were measured with the same calipers by penetrating the mucosa to the surface of the bone facially and palatally.

Intrasulcular incisions were made to sever the gingival attachment from the neck of the tooth circumferentially. The teeth were extracted without flap elevation using periotomes and fine luxators applied to the palatal aspects of the teeth (fig 2a). Fine tipped forceps were used with rotational movements only to avoid facially directed pressure on the socket wall. The sockets were debrided with surgical curettes to remove soft tissue tags or remnants of granulation tissue. The facial bone walls were 
examined from the inner aspect of the socket with a periodontal probe to confirm that they were intact and undamaged.

Immediately following tooth extraction, the distance between the template and the bone crest at the mesiofacial, midfacial, distofacial, mesiopalatal, midpalatal and distopalatal aspects of the sockets were recorded.

ARP was then performed using $90 \%$ deproteinized bovine bone mineral in a $10 \%$ collagen matrix (DBBMC) (Geistlich Bio-Oss $®$ Collagen, Geistlich Pharma AG, Wolhusen, Switzerland). The graft was prepared by soaking in sterile saline for several minutes before filling the socket. The graft was gently packed into the socket to the level of the facial bone crest with hand instruments (fig $2 b$ ). The socket entrance was closed with a resorbable type $\mathrm{I} / \mathrm{III}$ porcine collagen matrix (CM) (Geistlich Mucograft® Seal, Geistlich Pharma AG, Wolhusen, Switzerland) that was sutured into position (fig 2c). A removable partial denture or vacuum-formed removable prosthesis was then delivered, with care taken to ensure that the removable prosthesis did not exert pressure on the crestal or facial region of the socket. Patients were instructed to use a $0.2 \%$ chlorhexidine mouthrinse (Curasept ADS 220; Curaden AG, Kriens, Switzerland) and to avoid brushing the surgical site for 2 weeks. Patients returned 2 weeks after surgery for removal of sutures. The patients were then scheduled for implant surgery 8 to 10 weeks following extraction and ARP (fig 2d). Pre-operative CBCT were obtained at this time using the same radiological parameters as described previously. Following administration of local anesthesia (2\% lignocaine hydrochloride; 1:100,000 adrenaline), measurements of the external soft tissue and bone dimensions of the ridges were repeated in the same manner as described previously. Two-sided full thickness mucoperiosteal flaps were raised on the facial aspect with a vertical releasing incision on the distal aspect of the lateral incisors adjacent to the missing tooth sites (fig 2e). On the palatal side, flap elevation was performed to only expose the palatal bone margins. The distances between the template and the bone crest at the mesiofacial, mid-facial, distofacial, mesiopalatal, mid-palatal and disto- palatal aspects of the sockets were once again recorded. The implant osteotomies were then prepared according to the manufacturer's recommendation (fig $2 \mathrm{f}$ ), and implants with a standard $4.1 \mathrm{~mm}$ diameter and 10 to $12 \mathrm{~mm}$ in length were inserted in the correct 3-dimensional position (Straumann RC bone level implants; Straumann AG, Basel, Switzerland) (fig $2 \mathrm{~g}$ ). Additional grafting of the facial aspect of the ridge was performed if it was determined that additional soft tissue support at the shoulder region was required for soft tissue support and aesthetics. The additional grafting was completed grating was using particulate deproteinized bovine bone mineral 
(DBBM) (Geistlich Bio-Oss $®$; Geistlich Pharma AG, Wolhusen, Switzerland) and a resorbable native bilayer collagen barrier membrane (NBCM) (Geistlich Bio-Gide $\AA$; Geistlich Pharma AG, Wolhusen, Switzerland) (fig $2 \mathrm{~h}$ ). Flaps were closed to fully submerge the implants. After a healing period of 3 months, the coronal regions of the implants were accessed by removing a plug of soft tissue over the ridge crest with a $15 \mathrm{C}$ scalpel blade to facilitate the connection of transmucosal healing abutments. Restorative procedures then commenced (fig $2 \mathrm{i}$ ) and were reviewed immediately after connection of the prosthesis, and then 1 year later. Soft tissue aesthetic outcomes at one-year post-restoration were assessed using the Pink Esthetic Score (Furhauser et al., 2005).

\section{CBCT measurements}

The CBCT analysis was performed by one examiner (SC). The DICOM files were imported into an image analysis software program (OnDemand3D; Cybermed Inc., Seoul, Korea). After defining the region of interest (ROI), the 3D mutiplanar reconstruction (MPR) mode was launched, revealing axial, coronal and sagittal slices. The software automatically superimposed axial, sagittal and coronal orientation lines on the images. The images were rotated and adjusted to achieve the following reproducible reference lines:

In the axial view, a mesiodistal reference line that bisected the root canals of the teeth adjacent to the site of interest was drawn. The apicocoronal position of this line was adjusted in the coronal view to be located at the CEJ of the adjacent teeth when viewed in the sagittal plane. In most cases, this line was also at the level of the CEJ of the tooth of interest. In the coronal view, the image was rotated so that an apicocoronal reference was parallel to the tooth of interest and coincident with the axes of the adjacent teeth when viewed in the sagittal plane.

The planes and reference lines were based on the adjacent teeth rather than on the tooth to be extracted, thereby allowing the same reference points and planar axes to be used on the post-extraction/ARP scans (fig 3).

In the sagittal view at the site of interest, orofacial measurements of the ridge perpendicular to the apicocoronal reference line were then obtained using the linear measurement tool, at $1 \mathrm{~mm}$ increments apical to the mesiodistal reference line from 0 to $10 \mathrm{~mm}$ (fig $4 \mathrm{a}$-and $4 \mathrm{~b}$ ).

The area of the alveolar ridge was derived using the area tool of the software. A line was drawn to connect the facial and palatal bone crests. The line was extended on the facial aspect to trace the outer surface of the facial bone. The line extended apically to the horizontal measurement line that coincided with the apex of the root. 
The line was then extended onto the palatal surface of the bone to coronally meet the palatal bone crest. Thus, the outline of the alveolar bone was traced as an irregular shape from which the area was provided as an output by the software program. These measurements were repeated for the post-extraction/ARP CBCT data. All measurements were made by one experienced examiner (SC). 3 cases were measured 1 week apart. The intra-observer reproducibility was assessed by intraclass correlation coefficient (ICC) to be 0.99 . The standard error was $0.49 \mathrm{~mm}$.

\section{Data analysis}

Descriptive methods were used to summarize patient demographics. For continuous data, residuals for individual parameters were plotted to confirm normality of the distributions. Differences between pretreatment and re-entry data were analysed with the paired Student's t-test. The level of significance was set at 0.05 . All analyses were carried out using the statistical package Minitab (Minitab 18, Minitab Inc., Philadelphia, USA).

\section{Results}

\section{Patient demographics}

Over a 14-month recruitment period, a total of 10 consecutive patients who fulfilled the inclusion criteria were included in the study. All patients who were intended to be treated received the prescribed treatment with no exclusions. There were 5 female and 5 male patients, with an average age of $42.9 \pm 19.37$ years (range 21.7 to 71.7 years). Each patient contributed one maxillary central incisor extraction site. All 10 patients that were enrolled underwent the planned treatment without deviation to the protocol. The gingival phenotype was thick in 2 patients, medium in 4 patients and thin in 4 patients.

\section{Clinical outcomes}

Extraction, ARP and the subsequent healing proceeded uneventfully in all cases. Patients returned for the placement of implants after a mean time of $8.9 \pm 0.97$ weeks (range 8.0 to 10.6 weeks). At this time, the mucosa was observed to have completely healed with formation of an epithelized soft tissue barrier at all sites, and were free of signs of inflammation, infection or scar formation. In 9 cases, a soft tissue invagination at the crestal region representing about $10-20 \%$ the size of the 
original socket size was present. The mucosa appeared less mature within the invagination. In some cases, particles of exfoliating DBBMC could be seen at the surface of the invagination without any sign of infection. All sites demonstrated varying degrees of facial resorption of the ridge in the coronal region.

On flap reflection, the sockets were completely filled with the DBBMC graft. The superficial region of the graft did not appear to be fully ossified, and was contained within a fibrous connective tissue matrix. This immature tissue was not removed. There was sufficient bone volume to allow the placement of implants in the correct 3dimensional position in all 10 sites. During preparation of the implant osteotomy, it was observed that the graft material remained intact and did not dislodge or disperse from the site.

In one case, however, a dehiscence of the facial bone occurred when the osteotomy was prepared, indicating a relative lack of orofacial bone dimension in this one case. All implants were $4.1 \mathrm{~mm}$ in diameter (Straumann regular CrossFit RC SLActive implants; Straumann AG, Switzerland) with lengths of $10 \mathrm{~mm}$ (5 sites) and $12 \mathrm{~mm}$ (5 sites). Following implant placement, all sites were determined to have insufficient facial ridge contour for aesthetic outcomes. Additional low volume grafting of the facial aspect of the ridge was carried for contour augmentation at each site. All implants were stable and clinically integrated after 3 months. At this time, the patients returned to their referring dental practitioners who completed restoration of the implants with single implant crowns 1 to 2 months later.

\section{Intra-operative measurements}

Alterations in the dimensions of the ridge between extraction/ARP and surgical reentry are presented in table 1.

Pre-treatment, the mean thickness of the facial bone wall was $0.8 \pm 0.38 \mathrm{~mm}$ (median $0.7 \mathrm{~mm}$; range 0.5 to $1.7 \mathrm{~mm}$ ) at $5 \mathrm{~mm}$ apical to the CEJ. Only one site had a facial bone wall thickness of $>1 \mathrm{~mm}$.

There was a significant reduction in the external orofacial dimension of the ridge at the mid-facial aspect $(1.4 \pm 1.07 \mathrm{~mm}$; range 0 to $2 \mathrm{~mm}$ ) which represented a $13.2 \%$ reduction in the original ridge width $(p=0.003)$. At the mesial and distal aspects, the reduction observed was not statistically significant. There was also a statistically significant reduction in the orofacial bone dimension at the mid-facial aspect $(0.7 \pm$ $0.67 \mathrm{~mm}$; range 0 to $2 \mathrm{~mm} ; \mathrm{p}=0.010$ ) which amounted to $9.3 \%$ of the original 
orofacial bone width. The corresponding reduction observed on the mesial and distal aspects was not statistically significant.

Between extraction/ARP and surgical re-entry, there was significant apicocoronal reduction in height of the crestal bone at the midfacial $(1.2 \pm 0.78 \mathrm{~mm} ; \mathrm{p}=0.001)$, mesiopalatal $(0.7 \pm 0.67 \mathrm{~mm} ; p=0.004)$, midpalatal $(1.0 \pm 0.81 \mathrm{~mm} ; p=0.004)$ and distopalatal $(0.7 \pm 0.48 \mathrm{~mm} ; \mathrm{p}=0.001)$ aspects of the socket.

\section{CBCT analysis}

The CBCT assessment of orofacial bone dimensions were measured at $1 \mathrm{~mm}$ increments apical to the CEJ (table 2). Pre-extraction, there were no sites with facial bone at 1 and $2 \mathrm{~mm}$ apical to the CEJ. At 3, 4 and $5 \mathrm{~mm}$ apical to the CEJ, a facial bone wall was observed in 5,8 and 9 sites respectively. From $6 \mathrm{~mm}$ to $10 \mathrm{~mm}$ apical to the CEJ, all 10 sites had facial bone detectable on preoperative CBCT. The comparison between $\mathrm{CBCT}$ at the two time points revealed a significant reduction in orofacial bone dimensions at 4 to $10 \mathrm{~mm}$ apical to the CEJ, ranging from 1.0 to 1.7 $\mathrm{mm}$, or 7.3 to $18.6 \%$ reduction in the original orofacial bone width. There was a trend for a greater reduction in bone width in the coronal half compared to the apical half of the alveolar ridge.

The total alveolar ridge area showed a statistically significant reduction of $10.9 \pm$ $13.42 \mathrm{~mm}^{2}$, or $12.2 \%$ change (range 1.4 to $29.9 \mathrm{~mm}^{2} ; \mathrm{p}=0.030$ ).

\section{Follow-up}

At the one-year follow-up post-restoration, the implant survival rate was $100 \%$. One implant developed mucositis and a fistula on the facial aspect that required treatment, yielding a one-year success rate of $90 \%$. One implant demonstrated minor bleeding after probing at the mid-facial aspect. Probing pockets at the implants were with normal limits (mean $2.4 \pm 0.34 \mathrm{~mm}$ ). At one-year post-restoration, the median Pink Esthetic Score was 10 (range 9 - 13).

\section{Discussion}

In this study, ARP was performed on single maxillary central incisor sockets of 10 consecutively enrolled patients. It was noted that the clinical handling of the graft material at an early time point of 8 to 10 weeks after extraction/ARP was favourable. The graft remained intact and did not dislodge or disperse while the osteotomy was being prepared. All sites retained sufficient bone volume to allow implants to be placed between 8 to 10 weeks after ARP. These findings are consistent with reports from previous studies, confirming that ARP is an effective treatment for maintaining 
sufficient bone volume to facilitate the subsequent placement of implants (Araujo et al., 2014; Barone et al., 2008; Carmagnola, Adriaens, \& Berglundh, 2003; lasella et al., 2003; Mardas et al., 2010). However, as reported in previous systematic reviews, ARP does not prevent dimensional alterations but does limit the extent to which this occurs (Avila-Ortiz, Elangovan, Kramer, Blanchette, \& Dawson, 2014; Bassir et al., 2018; MacBeth et al., 2017; Mardas et al., 2015; Vignoletti et al., 2012; Willenbacher, Al-Nawas, Berres, Kammerer, \& Schiegnitz, 2016). In the present study, a significant reduction in external ridge $(13.2 \%)$ and bone dimensions $(9.3 \%)$ were observed at the reference level ( $5 \mathrm{~mm}$ apical to the gingival margin). The reduction in orofacial bone width on CBCT ranged from 7.3 to $18.6 \%$ along the corono-apical height of the alveolar process, with greater dimensional change in the coronal half compared to the apical half. These findings are largely in agreement with other studies of ARP using DBBMC graft (Cosyn et al., 2016; Jung et al., 2013) and similar to a study that used a combination allograft and xenograft (Serrano, Castellanos, \& Botticelli, 2018). However, a recent study using the same DBBMC graft reported orofacial reduction of $0.62 \pm 0.32,0.40 \pm 0.26$ and $0.10 \pm 0.08 \mathrm{~mm}$ at $1 \mathrm{~mm}, 3 \mathrm{~mm}$ and $5 \mathrm{~mm}$ apical to the bone crest 4 months after extraction/ARP (Cardaropoli, Tamagnone, Roffredo, De Maria, \& Gaveglio, 2018). This was much less than that reported in the present study, where the linear dimensional changes were $>1 \mathrm{~mm}$ along the entire apicocoronal dimension of the alveolar process. The difference between studies may be attributable to methodical differences in determining the reference planes in the sagittal CBCT images, with adjacent teeth serving as fixed reference points in the present study compared to the axis of the extraction socket at the test site by Cardaropoli and co-workers. Furthermore, the inclusion of maxillary incisors, canines and premolars by Cardaropoli and co-workers compared to only maxillary central incisors in the present study may be another reason for the difference between studies, since post-grafting resorption has reported to be greater at central incisors and cuspids, compared to lateral incisors and premolars (Cosyn et al., 2016). It is interesting to note the similarity of the intra-operative reduction in orofacial bone width of $9.3 \%$ at the MD reference level located $5 \mathrm{~mm}$ from the gingival margin and the reduction of $12.6 \%$ on CBCT at $5 \mathrm{~mm}$ from the CEJ. Although not identical in location, the reference points are in a similar position at the alveolar ridge. This suggests that $\mathrm{CBCT}$ measurements of ridge dimension change could be a useful non-invasive surrogate for intra-operative measurements. However, this approach should be interpreted cautiously, since CBCT scans may distinguish cortical bone clearly, but less clearly delineate trabecular or woven bone which may form part of the healing socket wall (Araujo 2014). 
Although all sites retained sufficient bone volume to allow implants with a standard $4.1 \mathrm{~mm}$ diameter and 10 to $12 \mathrm{~mm}$ in length to be placed, a dehiscence of the facial aspect of the implant occurred in one case. This observation is consistent with reports that the volume of bone preserved with ARP may not always be sufficient to ensure that implants are completely placed within intact bone walls, thereby requiring further bone augmentation at the time of implant placement (Barone, Ricci, Tonelli, Santini, \& Covani, 2012; Eskow \& Mealey, 2014; Koutouzis \& Lipton, 2016). In contrast, other studies of ARP observed that implant placement could proceed without the need for further bone augmentation (Cosyn et al., 2016; lasella et al., 2003; Pang et al., 2016; Serino, Biancu, lezzi, \& Piattelli, 2003). The contrasting findings are likely due to the heterogeneity of tooth sites, pre-extraction condition of the socket walls, biomaterials used for ARP, healing periods, and methodological differences in recording clinical and radiological dimensional alterations, making it difficult for meaningful comparisons to be made (Balli et al., 2018). A clinically significant observation in this study was that additional grafting to further augment the facial contour of the ridge was required, as the extent of the preservation of bone and soft tissue volume in the coronal region of the ridge was determined clinically to be insufficient to ensure satisfactory aesthetic outcomes. The coronal region of the ridge underwent a $13.2 \%$ reduction in external orofacial dimension. The underlying bone reduction in the same region was $9.3 \%$. This degree of dimensional change is clinically significant and may adversely affect aesthetic outcomes if not compensated for. It has been reported that deficient tissue volume in the facial coronal region of the ridge may result in lack of facial ridge contour which in turn may cause a shadow at the cervical region of the implant prosthesis (Schneider, Grunder, Ender, Hammerle, \& Jung, 2011). Thus, supplementary augmentation procedures are often required to compensate for lack of tissue volume. One option is to place a connective tissue graft (CTG) at the coronal marginal region of the implant, either at the time the implant is placed (Boardman, Darby, \& Chen, 2015; Schneider et al., 2011) or at the time of connection of the provisional prosthesis after integration of the implant (Cosyn 2016, Eghbali 2018). In a 5-year report, all 32 implants in 32 ARP treated patients required a CTG for supplementary augmentation at the time of provisional crown insertion (Eghbali 2018). This study confirms that lack of tissue volume should be an expected outcome with ARP in aesthetic areas. In the present study, however, compensatory augmentation was performed using additional DBBM at the time of implant placement using the GBR contour augmentation technique originally described in conjunction with early (type 2) implant placement (Buser et al., 2008) as it has been shown to effectively maintain bone volume and soft tissue 
stability on the facial aspect of implants after 10 years (Chappuis et al., 2018). Although this approach avoids the need for a second surgical site to harvest a CTG, the disadvantage is the need for additional DBBM and the associated increase in the cost burden to the patient.

In the present study, CM was placed over the DBBMC to provide an initial barrier and to subsequently promote soft tissue closure over the socket. The CM undergoes a substitution process and is replaced with a vascularized collagen-rich connective tissue (Maiorana et al., 2017). Although fully epithelialized, the soft tissue invagination observed at $9 / 10$ cases after 8 to 10 weeks of healing indicates that the mucosa had not fully healed. This is consistent with a clinical study that used a soft tissue healing index to evaluate the healing extraction sockets with $\mathrm{CM}$ placed over DBBMC in 7 patients (Maiorana et al., 2017). At 4 weeks, there were no sites that had completely healed, whereas at 8 weeks, $5 / 7$ sites had healed completely. By 10 weeks, all sites had healed completely with full soft tissue closure.

In the present study, all implants were stable 3 months after placement and were subsequently restored without loss. All implants were integrated 12 months after restoration. These initial results suggest that early implant placement 8 to 10 weeks after grafting with $\mathrm{DBBMC} / \mathrm{CM}$ is viable, and may have a patient-centred benefit in reducing the duration of the overall treatment. Since the clinical and radiographic examination was done by one observer (SC), there is a risk of investigator bias which should be taken in to account when interpreting the results. This was mitigated, however, by blinding of patient identity during the CBCT analysis. This study is further limited by the relatively small number of cases and lack of a comparative group. Longer term studies designed to compare early implant placement after ARP using $\mathrm{DBBM} / \mathrm{CM}$ with other placement protocols are required to validate this approach.

\section{Conclusions}

In this study, ARP using DBBMC/CM maintained sufficient bone volume in maxillary central incisor extraction sites for the subsequent early placement of implants 8 to 10 weeks later. Healing after ARP was characterized by a significant reduction in orofacial ridge (13.2\%) and bone $(9.3 \%)$ dimensions at the mid-facial coronal region, and a reduction in apicocoronal height of the crestal bone at the midfacial (1.2 \pm 0.78 $\mathrm{mm}$ ) and palatal aspects of the socket. CBCT data indicated a concomitant reduction in orofacial bone dimensions at 4 to $10 \mathrm{~mm}$ apical to the CEJ ranging from 1.0 to 1.7 $\mathrm{mm}$ (representing 7.3 to $18.6 \%$ reduction in the original orofacial bone width) and a 
reduction in total alveolar ridge area of $10.9 \pm 13.42 \mathrm{~mm}^{2}(12.2 \%$ reduction $)$. Due to the reduced ridge dimensions in the coronal region, additional low volume grafting with DBBM/NBCM for contour augmentation was required for aesthetic reasons in 9/10 cases, whereas one case required more extensive grafting due to dehiscence formation when the osteotomy was prepared. All implants successfully integrated and were restored with a $100 \%$ survival rate one-year after restoration. Acceptable aesthetic outcomes were achieved (median Pink Esthetic Score 10; range 9 - 13. The early placement of implants following ARP using DBBMC and CM may be a viable treatment approach.

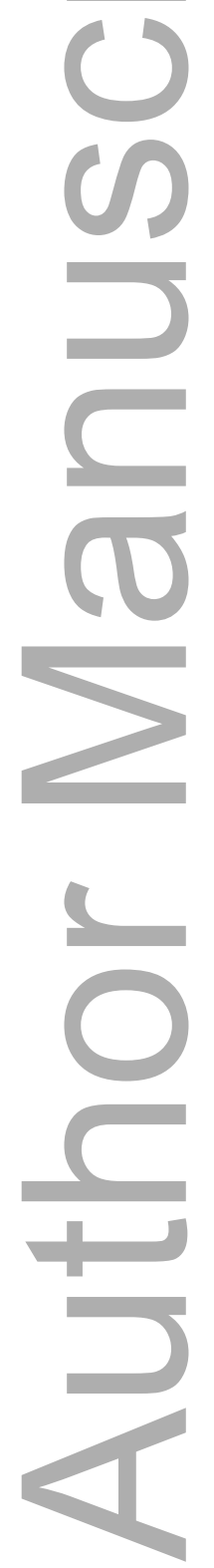

This article is protected by copyright. All rights reserved 


\section{References}

Araujo, M. G., da Silva, J. C., de Mendonca, A. F., \& Lindhe, J. (2014). Ridge alterations following grafting of fresh extraction sockets in man. A randomized clinical trial. Clin Oral Implants Res. doi:10.1111/clr.12366

Araujo, M. G., \& Lindhe, J. (2005). Dimensional ridge alterations following tooth extraction. An experimental study in the dog. J Clin Periodontol, 32(2), 212218.

Araujo, M. G., Sukekava, F., Wennstrom, J. L., \& Lindhe, J. (2005). Ridge alterations following implant placement in fresh extraction sockets: an experimental study in the dog. J Clin Periodontol, 32(6), 645-652.

Avila-Ortiz, G., Elangovan, S., Kramer, K. W., Blanchette, D., \& Dawson, D. V. (2014). Effect of alveolar ridge preservation after tooth extraction: a systematic review and meta-analysis. J Dent Res, 93(10), 950-958. doi:10.1177/0022034514541127

Balli, G., Ioannou, A., Powell, C. A., Angelov, N., Romanos, G. E., \& Soldatos, N. (2018). Ridge Preservation Procedures after Tooth Extractions: A Systematic Review. Int J Dent, 2018, 8546568. doi:10.1155/2018/8546568

Barone, A., Aldini, N. N., Fini, M., Giardino, R., Calvo Guirado, J. L., \& Covani, U. (2008). Xenograft versus extraction alone for ridge preservation after tooth removal: a clinical and histomorphometric study. J Periodontol, 79(8), 13701377. doi:10.1902/jop.2008.070628

Barone, A., Ricci, M., Tonelli, P., Santini, S., \& Covani, U. (2012). Tissue changes of extraction sockets in humans: a comparison of spontaneous healing vs. ridge preservation with secondary soft tissue healing. Clin Oral Implants Res. doi:10.1111/j.1600-0501.2012.02535.x

Bassir, S. H., Alhareky, M., Wangsrimongkol, B., Jia, Y., \& Karimbux, N. (2018). Systematic Review and Meta-Analysis of Hard Tissue Outcomes of Alveolar Ridge Preservation. Int J Oral Maxillofac Implants, 33(5), 979-994.

Boardman, N., Darby, I., \& Chen, S. (2015). A retrospective evaluation of aesthetic outcomes for single-tooth implants in the anterior maxilla. Clin Oral Implants Res. doi:10.1111/clr.12593

Brandam, L., Malmstrom, H., Javed, F., Calvo-Guirado, J. L., \& Romanos, G. E. (2015). Ridge Preservation Techniques in the Anterior Esthetic Zone. Implant Dent, 24(6), 699-712. doi:10.1097/ID.0000000000000341 
Buser, D., Bornstein, M. M., Weber, H. P., Grutter, L., Schmid, B., \& Belser, U. C. (2008). Early implant placement with simultaneous guided bone regeneration following single-tooth extraction in the esthetic zone: a cross-sectional, retrospective study in 45 subjects with a 2- to 4-year follow-up. J Periodontol, 79(9), 1773-1781. doi:10.1902/jop.2008.080071

Cardaropoli, D., Tamagnone, L., Roffredo, A., De Maria, A., \& Gaveglio, L. (2018). Alveolar Ridge Preservation Using Tridimensional Collagen Matrix and Deproteinized Bovine Bone Mineral in the Esthetic Area: A CBCT and Histologic Human Pilot Study. International Journal of Periodontics \& Restorative Dentistry, 38(Suppl), s29-s35. doi:10.11607/prd.3702

Carmagnola, D., Adriaens, P., \& Berglundh, T. (2003). Healing of human extraction sockets filled with Bio-Oss. Clin Oral Implants Res, 14(2), 137-143.

Chappuis, V., Rahman, L., Buser, R., Janner, S. F. M., Belser, U. C., \& Buser, D. (2018). Effectiveness of Contour Augmentation with Guided Bone Regeneration: 10-Year Results. J Dent Res, 97(3), 266-274. doi: $10.1177 / 0022034517737755$

Chen, S. T., \& Darby, I. (2017). The relationship between facial bone wall defects and dimensional alterations of the ridge following flapless tooth extraction in the anterior maxilla. Clin Oral Implants Res, 28(8), 931-937.

doi:10.1111/clr.12899

Cosyn, J., Cleymaet, R., \& De Bruyn, H. (2016). Predictors of Alveolar Process Remodeling Following Ridge Preservation in High-Risk Patients. Clin Implant Dent Relat Res, 18(2), 226-233. doi:10.1111/cid.12249

Covani, U., Cornelini, R., Calvo, J. L., Tonelli, P., \& Barone, A. (2010). Bone remodeling around implants placed in fresh extraction sockets. International Journal of Periodontics \& Restorative Dentistry, 30(6), 601-607.

Darby, I., Chen, S., \& De Poi, R. (2008). Ridge preservation: what is it and when should it be considered. Aust Dent J, 53(1), 11-21. doi:ADJ008 [pii]

10.1111/j.1834-7819.2007.00008.x

Darby, I., Chen, S. T., \& Buser, D. (2009). Ridge preservation techniques for implant therapy. Int J Oral Maxillofac Implants, 24 Suppl, 260-271.

Eghbali, A., Seyssens, L., De Bruyckere, T., Younes, F., Cleymaet, R., \& Cosyn, J. (2018). A 5-year prospective study on the clinical and aesthetic outcomes of alveolar ridge preservation and connective tissue graft at the buccal aspect of single implants. J Clin Periodontol, 45(12), 1475-1484.

doi:10.1111/jcpe.13018

This article is protected by copyright. All rights reserved 
Eskow, A. J., \& Mealey, B. L. (2014). Evaluation of healing following tooth extraction with ridge preservation using cortical versus cancellous freeze-dried bone allograft. J Periodontol, 85(4), 514-524. doi:10.1902/jop.2013.130178

Farmer, M., \& Darby, I. (2014). Ridge dimensional changes following single-tooth extraction in the aesthetic zone. Clin Oral Implants Res, 25(2), 272-277. doi:10.1111/clr.12108

Furhauser, R., Florescu, D., Benesch, T., Haas, R., Mailath, G., \& Watzek, G. (2005). Evaluation of soft tissue around single-tooth implant crowns: the pink esthetic score. Clin Oral Implants Res, 16(6), 639-644.

Hämmerle, C. H., Chen, S. T., \& Wilson, T. G., Jr. (2004). Consensus statements and recommended clinical procedures regarding the placement of implants in extraction sockets. Int J Oral Maxillofac Implants, 19 Suppl, 26-28.

lasella, J. M., Greenwell, H., Miller, R. L., Hill, M., Drisko, C., Bohra, A. A., \& Scheetz, J. P. (2003). Ridge preservation with freeze-dried bone allograft and a collagen membrane compared to extraction alone for implant site development: A clinical and histologic study in humans. J Periodontol, 74, 990-999.

Jung, R. E., Philipp, A., Annen, B. M., Signorelli, L., Thoma, D. S., Hammerle, C. H., . Schmidlin, P. (2013). Radiographic evaluation of different techniques for ridge preservation after tooth extraction: a randomized controlled clinical trial. JClin Periodontol, 40(1), 90-98. doi:10.1111/jcpe.12027

Koutouzis, T., \& Lipton, D. (2016). Regenerative Needs Following Alveolar Ridge Preservation Procedures in Compromised and Noncompromised Extraction Sockets: A Cone Beam Computed Tomography Study. Int J Oral Maxillofac Implants, 31(4), 849-854. doi:10.11607/jomi.4437

MacBeth, N., Trullenque-Eriksson, A., Donos, N., \& Mardas, N. (2017). Hard and soft tissue changes following alveolar ridge preservation: a systematic review. Clin Oral Implants Res, 28(8), 982-1004. doi:10.1111/clr.12911

Maiorana, C., Poli, P. P., Deflorian, M., Testori, T., Mandelli, F., Nagursky, H., \& Vinci, R. (2017). Alveolar socket preservation with demineralised bovine bone mineral and a collagen matrix. J Periodontal Implant Sci, 47(4), 194-210. doi:10.5051/jpis.2017.47.4.194

Mardas, N., Chadha, V., \& Donos, N. (2010). Alveolar ridge preservation with guided bone regeneration and a synthetic bone substitute or a bovine-derived xenograft: a randomized, controlled clinical trial. Clin Oral Implants Res, 21(7), 688-698. doi:CLR1918 [pii]

10.1111/j.1600-0501.2010.01918.x

This article is protected by copyright. All rights reserved 
Mardas, N., Trullenque-Eriksson, A., MacBeth, N., Petrie, A., \& Donos, N. (2015). Does ridge preservation following tooth extraction improve implant treatment outcomes: a systematic review: Group 4: Therapeutic concepts \& methods. Clin Oral Implants Res, 26 Suppl 11, 180-201. doi:10.1111/clr.12639

Morjaria, K. R., Wilson, R., \& Palmer, R. M. (2012). Bone Healing after Tooth Extraction with or without an Intervention: A Systematic Review of Randomized Controlled Trials. Clin Implant Dent Relat Res. doi:10.1111/j.1708-8208.2012.00450.x

Muller, H.P., Heinecke, A., Schaller, N., \& Eger, T. (2000). Masticatory mucosa in subjects with different periodontal phenotypes. J Clin Periodontol, 27(9), 621626.

Pang, C., Ding, Y., Hu, K., Zhou, H., Qin, R., \& Hou, R. (2016). Influence of preservation of the alveolar ridge on delayed implants after extraction of teeth with different defects in the buccal bone. Br J Oral Maxillofac Surg, 54(2), 176-180. doi:10.1016/j.bjoms.2015.11.025

Roccuzzo, M., Gaudioso, L., Bunino, M., \& Dalmasso, P. (2014). Long-term stability of soft tissues following alveolar ridge preservation: 10-year results of a prospective study around nonsubmerged implants. International Journal of Periodontics \& Restorative Dentistry, 34(6), 795-804. doi:10.11607/prd.2133

Scheyer, E. T., Heard, R., Janakievski, J., Mandelaris, G., Nevins, M. L., Pickering, S. R., ... Nagursky, H. (2016). A randomized, controlled, multicentre clinical trial of post-extraction alveolar ridge preservation. J Clin Periodontol, 43(12), 1188-1199. doi:10.1111/jcpe.12623

Schneider, D., Grunder, U., Ender, A., Hammerle, C. H., \& Jung, R. E. (2011). Volume gain and stability of peri-implant tissue following bone and soft tissue augmentation: 1-year results from a prospective cohort study. Clin Oral Implants Res, 22(1), 28-37.

Schropp, L., Wenzel, A., Kostopolous, L., \& Karring, T. (2003). Bone healing and soft tissue contour changes following single-tooth extraction: A clinical and radiographic 12-month prospective study. International Journal of Periodontics \& Restorative Dentistry, 23, 313-323.

Seibert, J. S., \& Salama, H. (1996). Alveolar ridge preservation and reconstruction. Periodontol 2000, 11, 69-84.

Serino, G., Biancu, S., lezzi, G., \& Piattelli, A. (2003). Ridge preservation following tooth extraction using a polylactide and polyglycolide sponge as space filler: a clinical and histological study in humans. Clin Oral Implants Res, 14(5), 651658.

This article is protected by copyright. All rights reserved 
Serrano, C. A., Castellanos, P., \& Botticelli, D. (2018). Use of Combination of Allografts and Xenografts for Alveolar Ridge Preservation Procedures: A Clinical and Histological Case Series. Implant Dent, 27(4), 467-473. doi:10.1097/ID.0000000000000792

Thoma, D. S., Naenni, N., Benic, G. I., Munoz, F., Hammerle, C. H. F., \& Jung, R. E. (2017). Effect of ridge preservation for early implant placement - is there a need to remove the biomaterial? J Clin Periodontol, 44(5), 556-565.

doi:10.1111/jcpe.12709

Vignoletti, F., Matesanz, P., Rodrigo, D., Figuero, E., Martin, C., \& Sanz, M. (2012). Surgical protocols for ridge preservation after tooth extraction. A systematic review. Clin Oral Implants Res, 23 Suppl 5, 22-38. doi:10.1111/j.16000501.2011.02331.x

Willenbacher, M., Al-Nawas, B., Berres, M., Kammerer, P. W., \& Schiegnitz, E. (2016). The Effects of Alveolar Ridge Preservation: A Meta-Analysis. Clin Implant Dent Relat Res, 18(6), 1248-1268. doi:10.1111/cid.12364

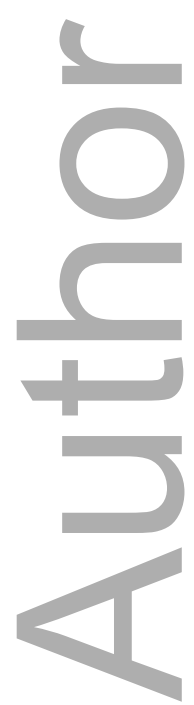

This article is protected by copyright. All rights reserved 
Table 1 - Change in orofacial ridge (surface of the soft tissue) and orofacial bone dimensions, and change in apicocoronal position of the bone crest

\begin{tabular}{|c|c|c|c|c|c|}
\hline$(1)$ & & $\begin{array}{c}\text { Mesial } \\
(\text { mean } \mathrm{mm} \pm \mathrm{sd}) \#\end{array}$ & $\begin{array}{c}\text { Mid-point } \\
(\text { mean } \mathrm{mm} \pm \mathrm{sd})\end{array}$ & $\begin{array}{c}\text { Distal } \\
(\text { mean } \mathrm{mm} \pm \mathrm{sd}) \#\end{array}$ & \\
\hline $\begin{array}{l}\text { Change in orofacial ridge (soft tissue } \\
\text { surface) dimension }\end{array}$ & & $0.4 \pm 0.69$ & $1.4 \pm 1.07^{*}$ & $0.1 \pm 0.47$ & ${ }^{*} p=0.003$ \\
\hline Change in orofacial bone dimension & & $0.1 \pm 0.56$ & $0.7 \pm 0.67^{* *}$ & $0.2 \pm 0.42$ & ${ }^{* *} p=0.010$ \\
\hline \multirow{2}{*}{$\begin{array}{l}\text { Change in apicocoronal position of the } \\
\text { bone crest }\end{array}$} & Facial & $0.5 \pm 0.71$ & $1.2 \pm 0.78^{* \star *}$ & $0.3 \pm 0.48$ & ${ }^{* *} p=0.001$ \\
\hline & Palatal & $0.7 \pm 0.67^{\wedge}$ & $1.0 \pm 0.81^{\wedge \wedge}$ & $0.7 \pm 0.48^{\wedge \wedge \wedge}$ & $\begin{array}{l}\wedge p=0.010 \\
{ }^{\wedge \wedge} p=0.004 \\
\wedge^{\wedge \wedge} p=0.001\end{array}$ \\
\hline
\end{tabular}

\# Positive value indicates a reduction in dimensions

sd $=$ standard deviation

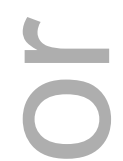

Table 2 - Change in orofacial bone dimensions assessed on CBCT at $1 \mathrm{~mm}$ increments from $3 \mathrm{~mm}$ apical to the CEJ

\begin{tabular}{|c|c|c|c|c|c|}
\hline & Position apical to the CEJ & $\mathrm{N}$ & $\begin{array}{l}\text { Mean change } \\
\qquad(\mathrm{mm} \pm \mathrm{sd})\end{array}$ & $\%$ change & \\
\hline \multirow{2}{*}{$\begin{array}{l}\text { Change in orofacial bone dimension } \\
\text { (midfacial position) }\end{array}$} & $3 \mathrm{~mm}$ & 5 & $1.6 \pm 1.34$ & 19.5 & $p=0.051$ (ns) \\
\hline & $4 \mathrm{~mm}$ & 8 & $1.7 \pm 0.63$ & 18.6 & $p=0.000$ \\
\hline
\end{tabular}

This article is protected by copyright. All rights reserved 


\begin{tabular}{|c|c|c|c|c|c|}
\hline \multirow{4}{*}{ צ' } & $5 \mathrm{~mm}$ & 9 & $1.1 \pm 0.44$ & 12.6 & $p=0.000$ \\
\hline & $6 \mathrm{~mm}$ & 10 & $1.6 \pm 1.86$ & 17.3 & $p=0.027$ \\
\hline & $7 \mathrm{~mm}$ & 10 & $1.3 \pm 1.55$ & 14.2 & $p=0.028$ \\
\hline & $8 \mathrm{~mm}$ & 10 & $1.2 \pm 1.28$ & 13.3 & $p=0.014$ \\
\hline a & $9 \mathrm{~mm}$ & 10 & $1.0 \pm 1.05$ & 10.7 & $\mathrm{p}=0.014$ \\
\hline & $10 \mathrm{~mm}$ & 10 & $1.7 \pm 0.69$ & 7.3 & $p=0.010$ \\
\hline
\end{tabular}

\# Positive value indicates a reduction in dimensions

$\mathrm{sd}=$ standard deviation

$\mathrm{ns}=$ not statistically significant

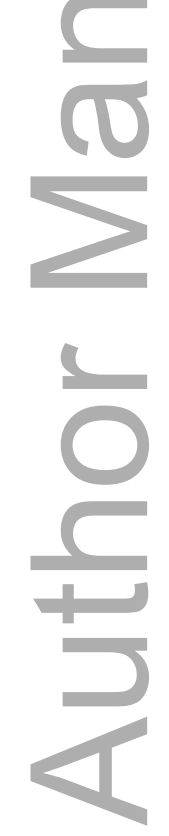

This article is protected by copyright. All rights reserved 


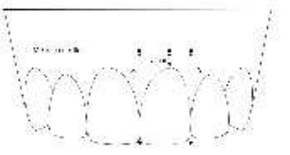

$$
\text { clr_13619_f1.tif }
$$
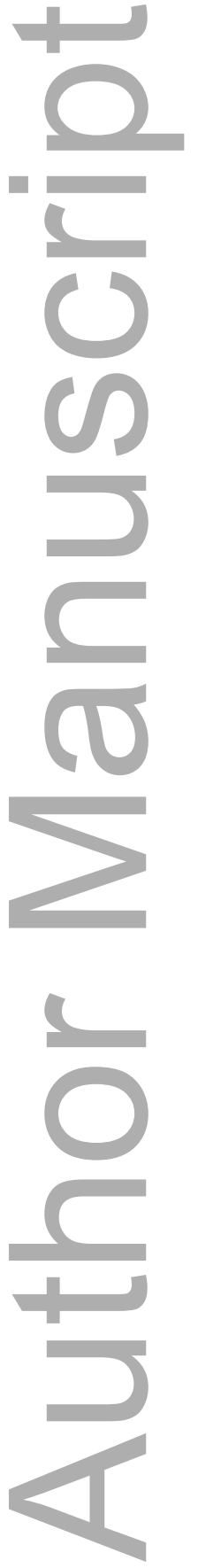

This article is protected by copyright. All rights reserved 

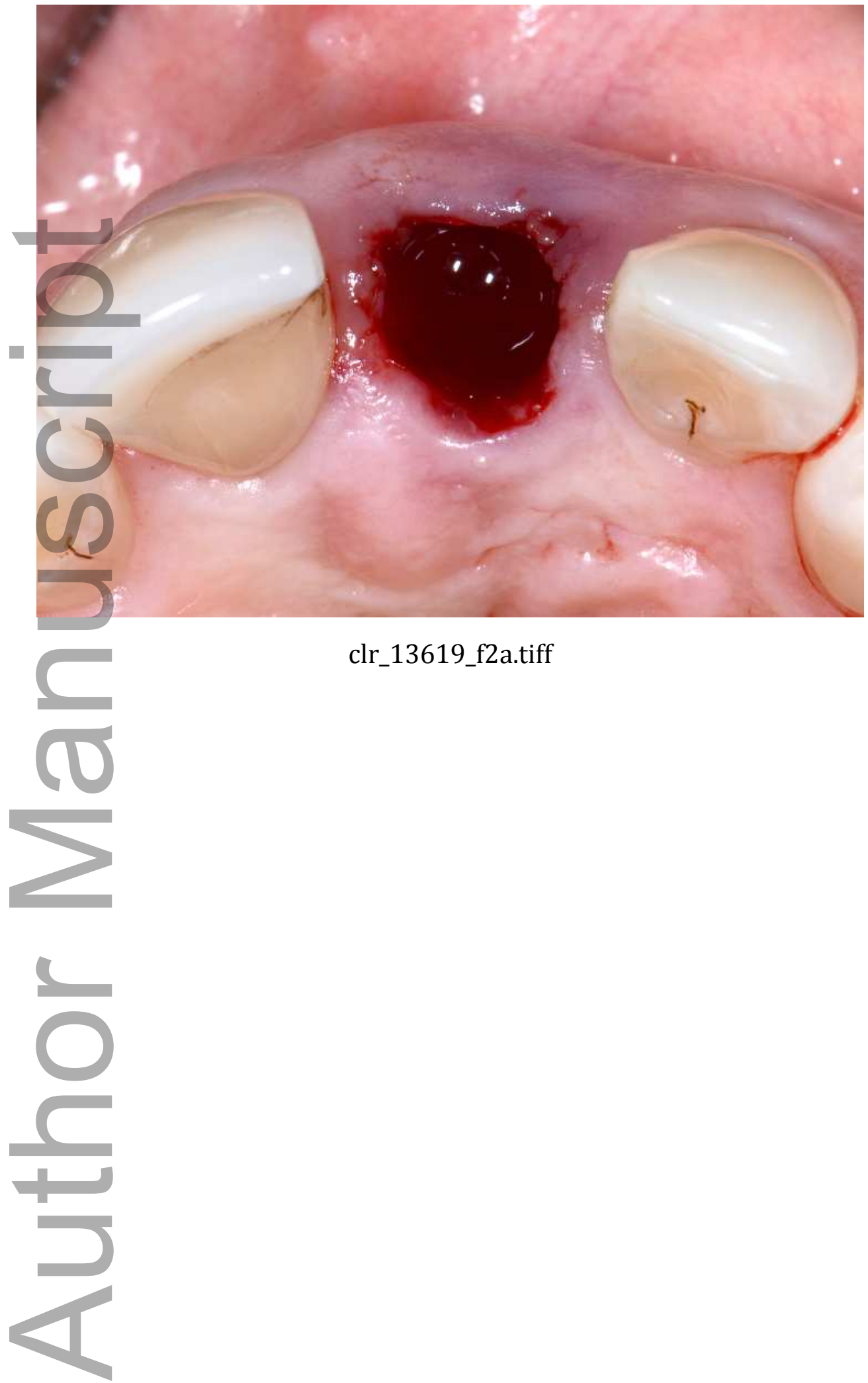

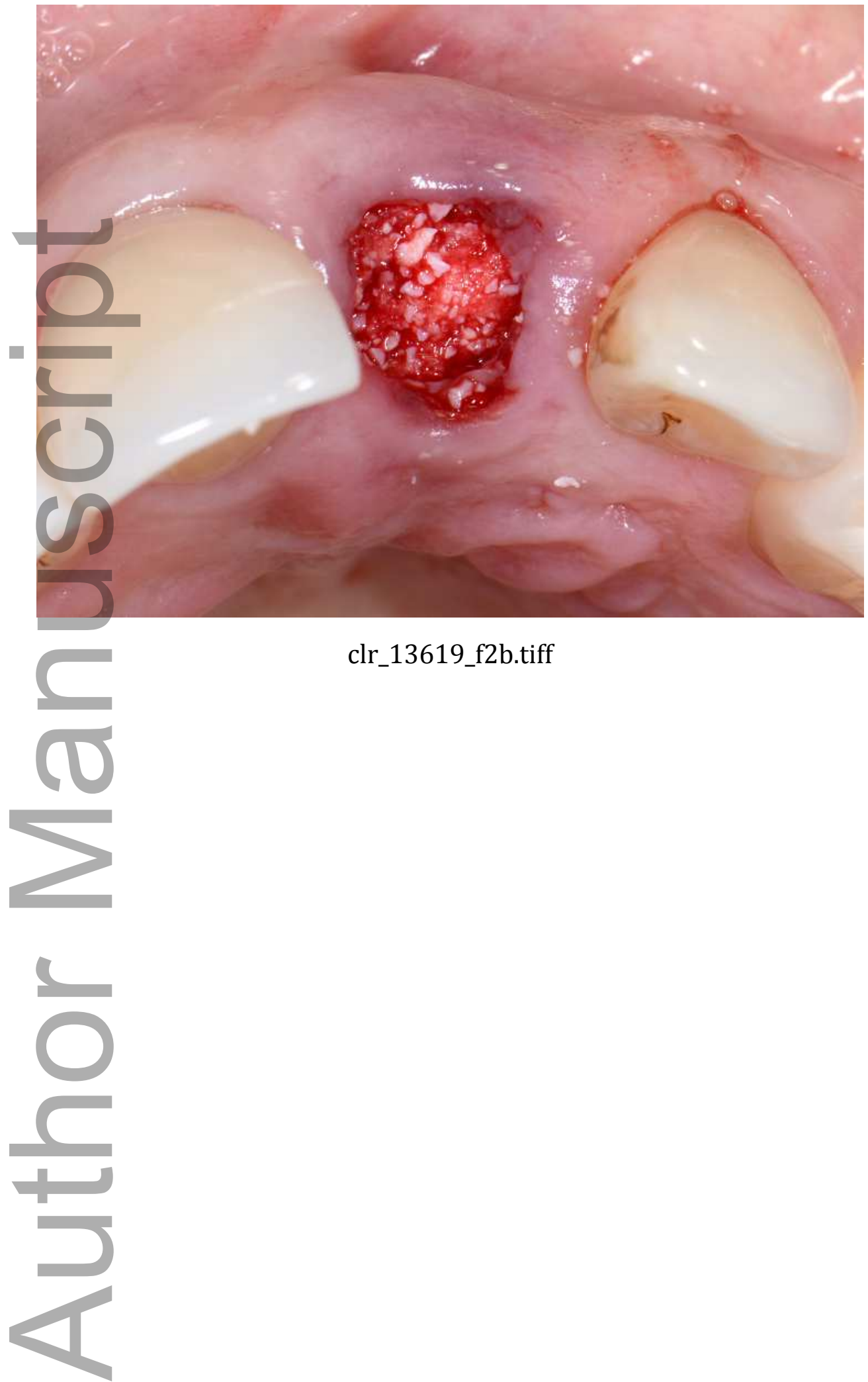

This article is protected by copyright. All rights reserved 

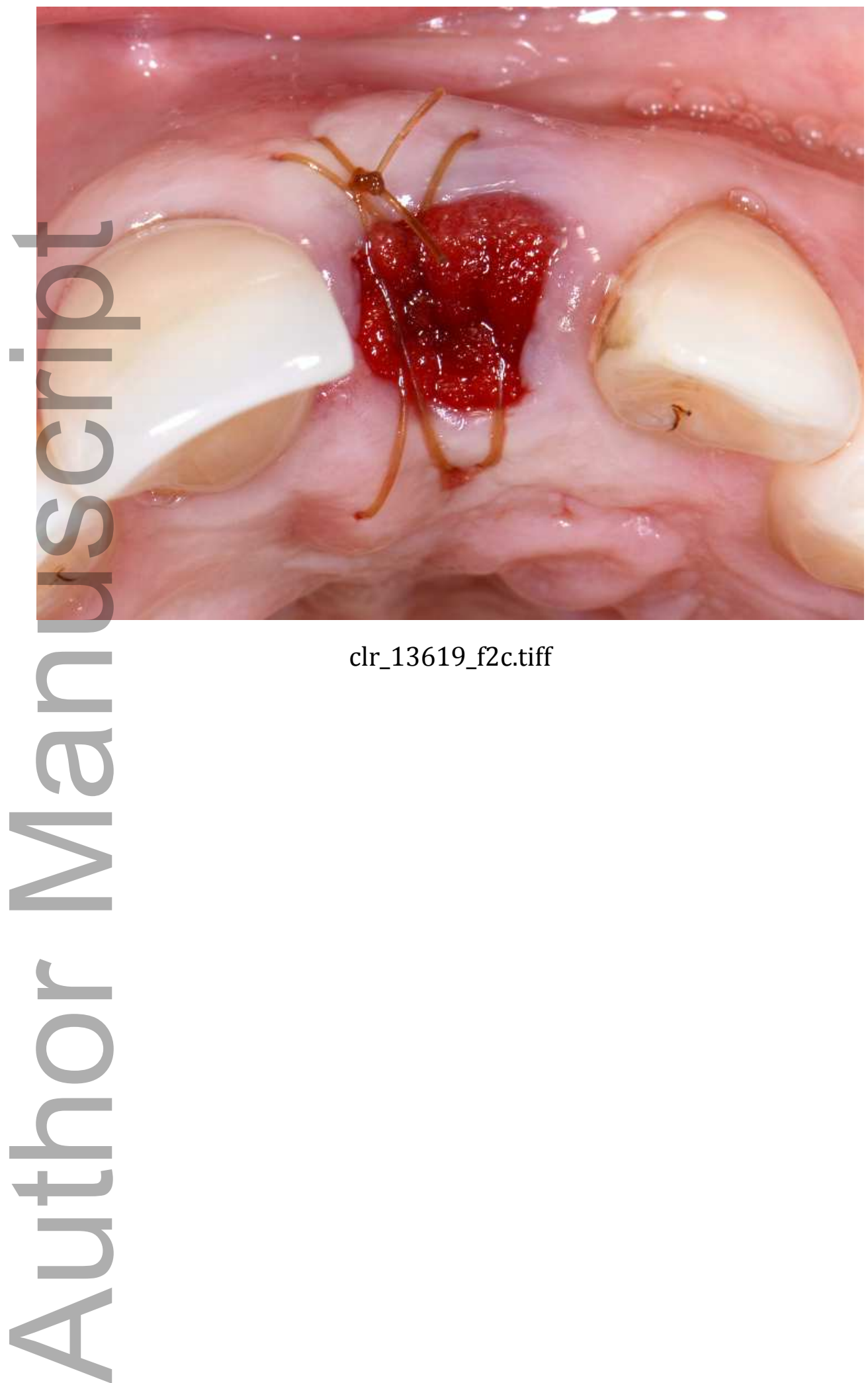

This article is protected by copyright. All rights reserved 

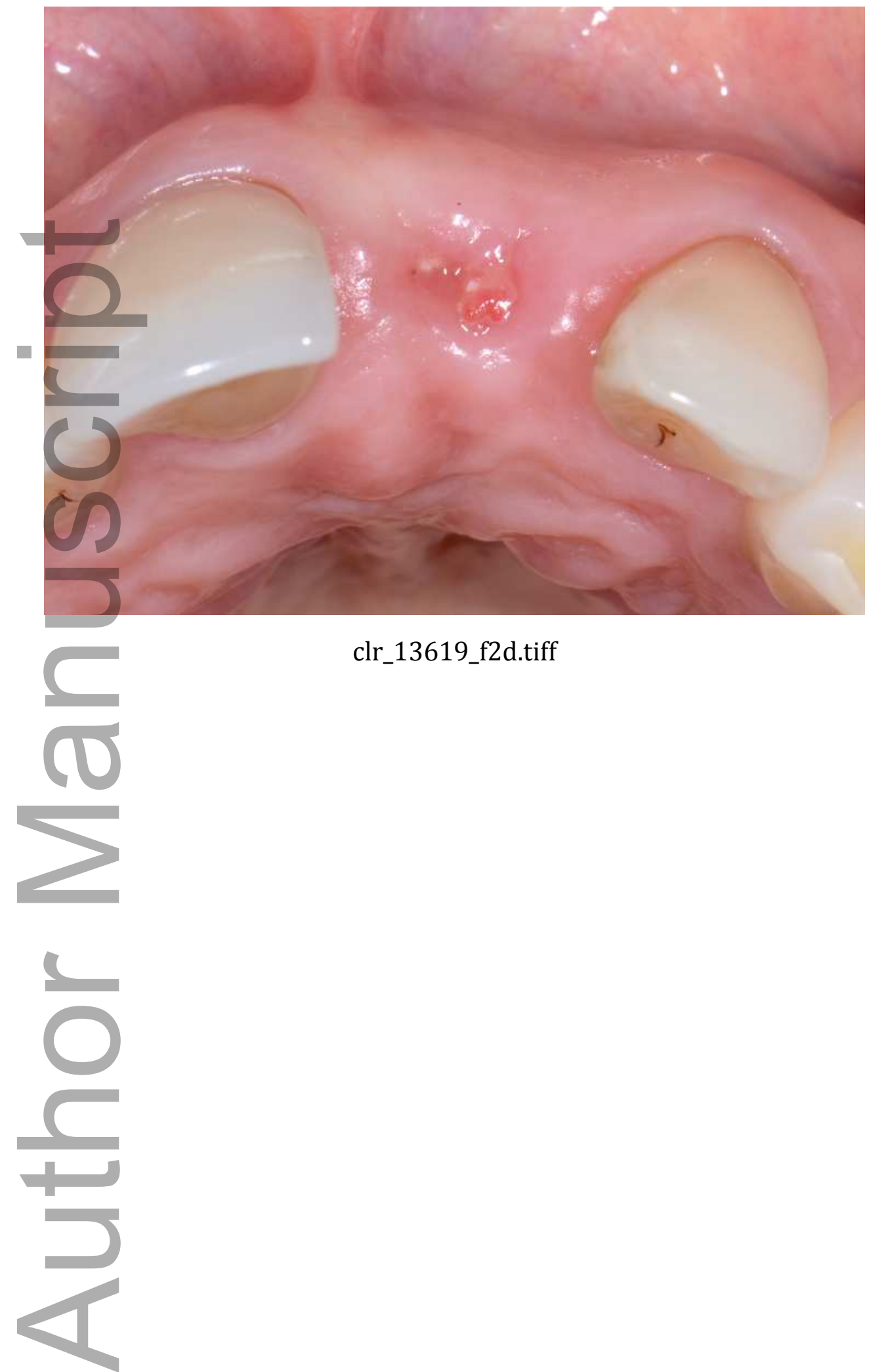

This article is protected by copyright. All rights reserved 

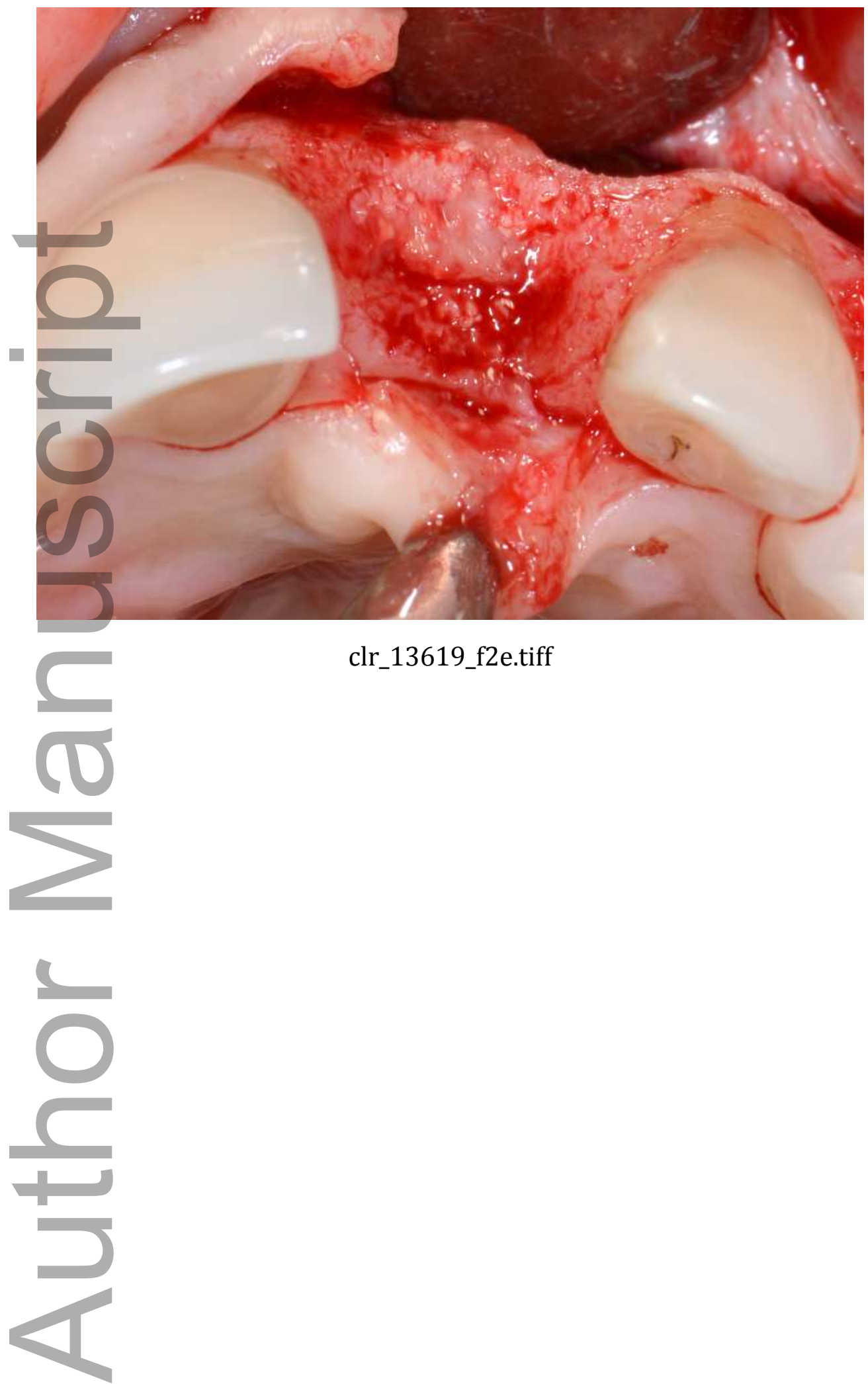

This article is protected by copyright. All rights reserved 


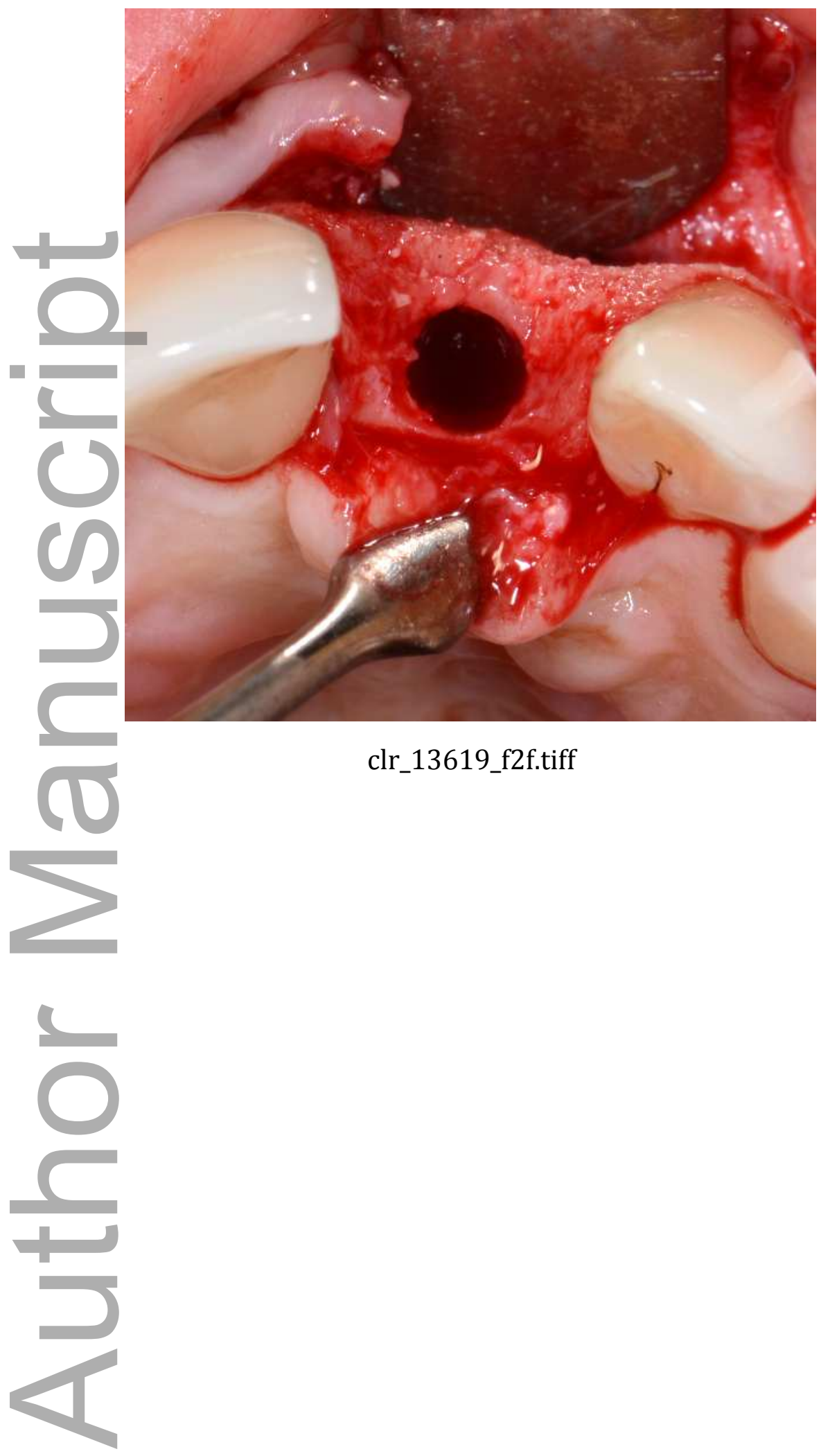

This article is protected by copyright. All rights reserved 

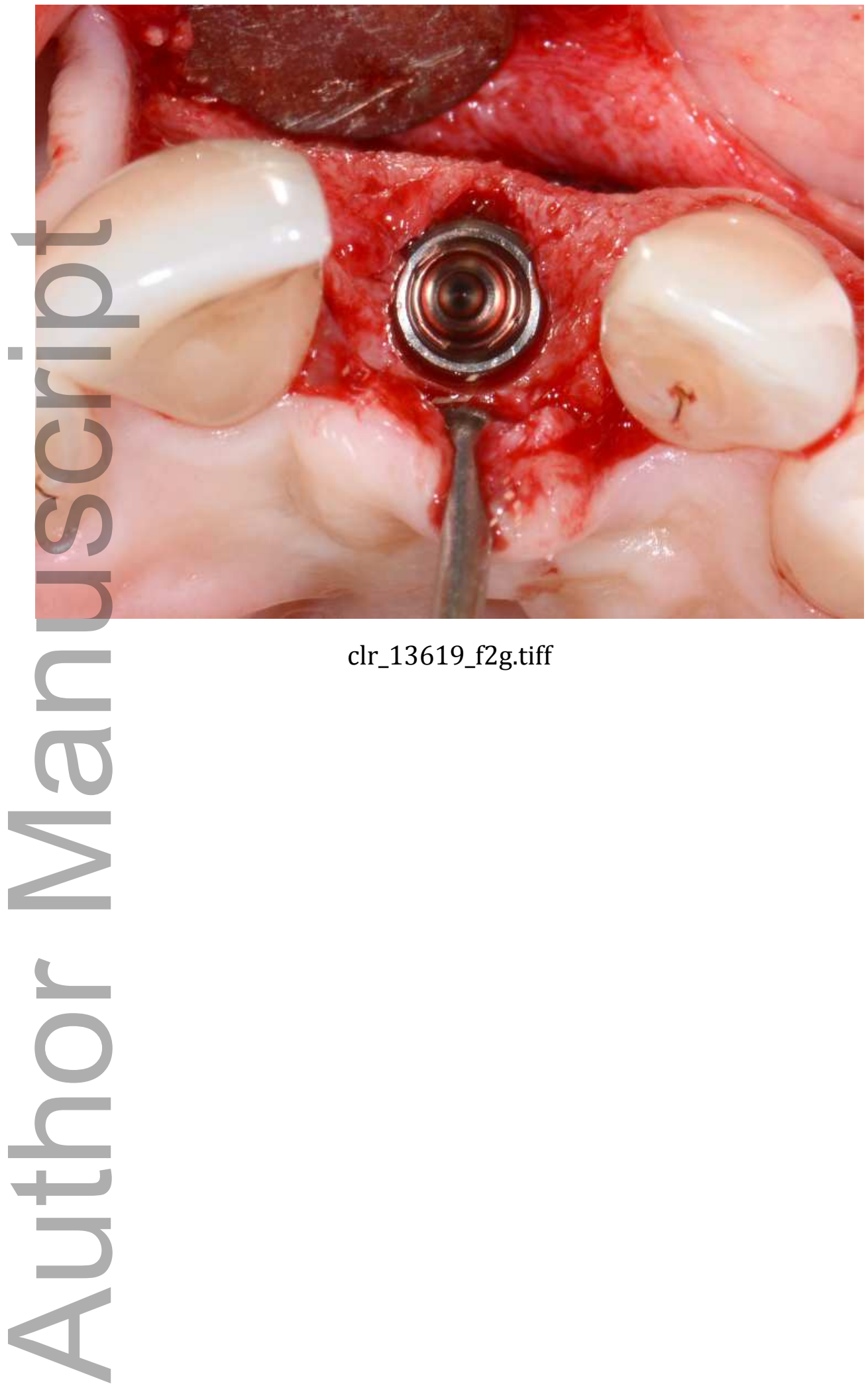

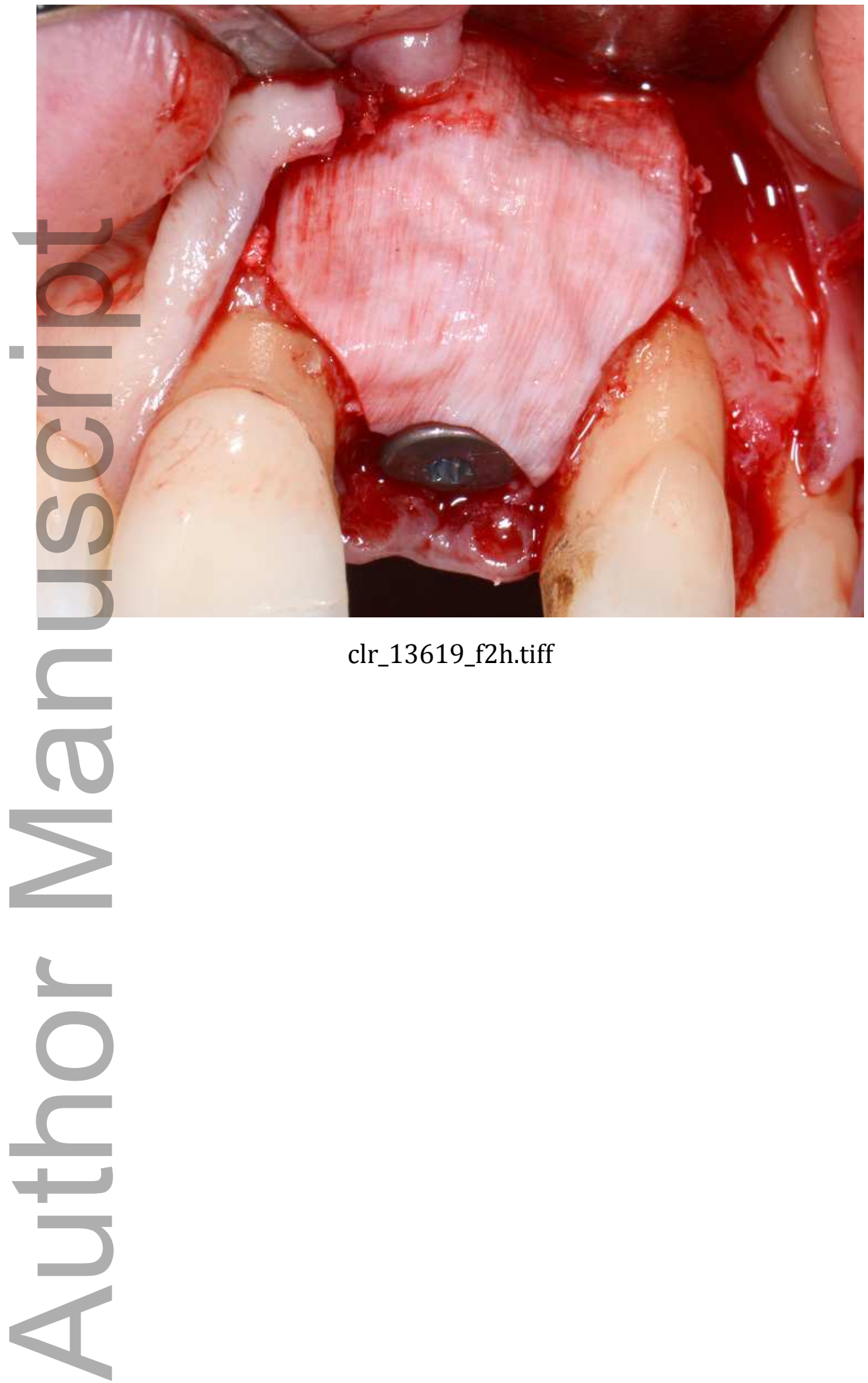

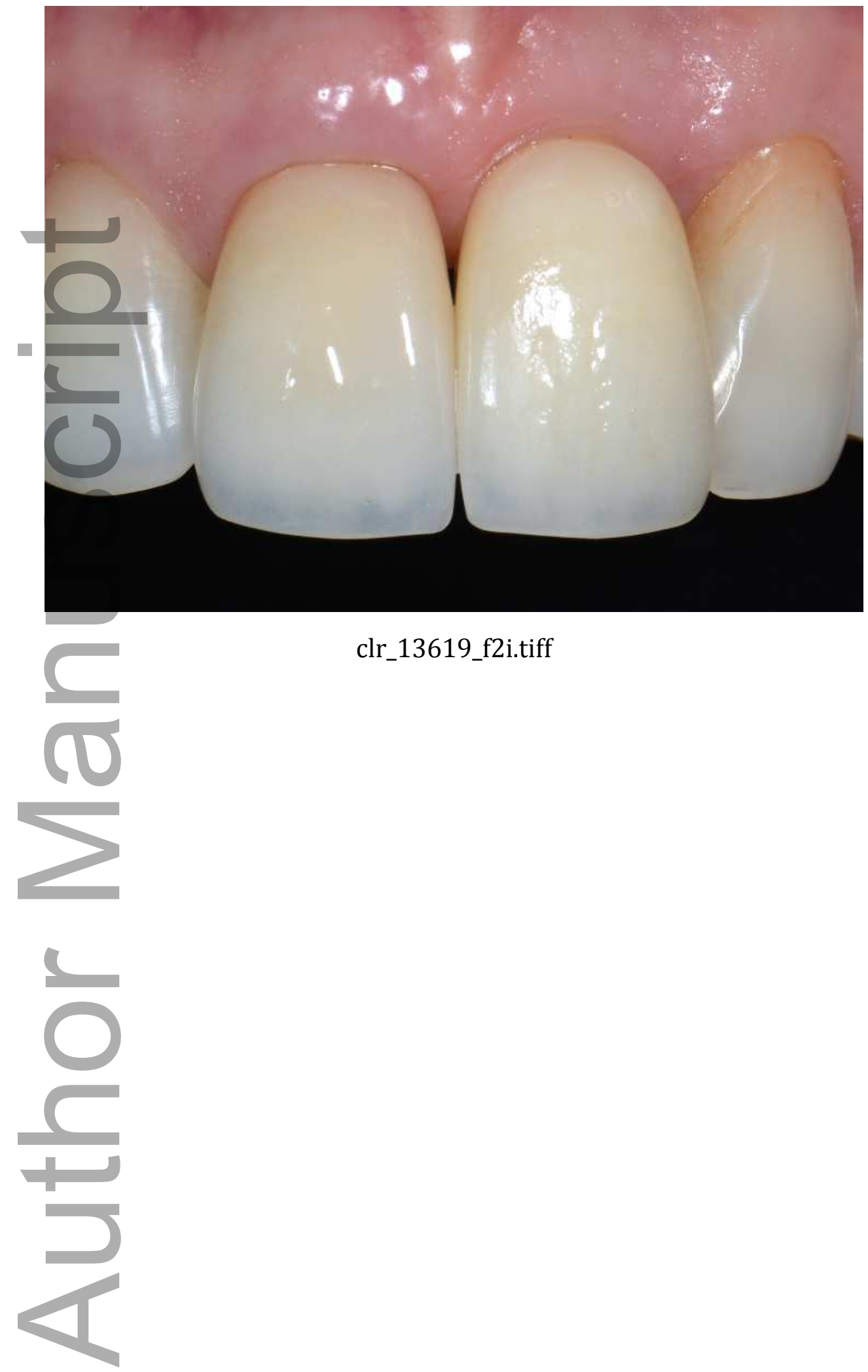

clr_13619_f2i.tiff 


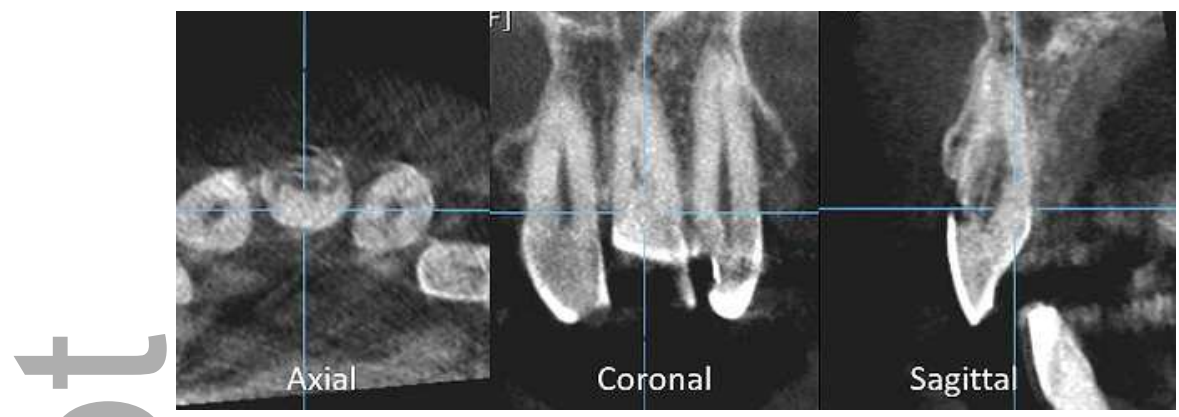

clr_13619_f3.tif

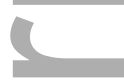

10

$\sqrt{2}$
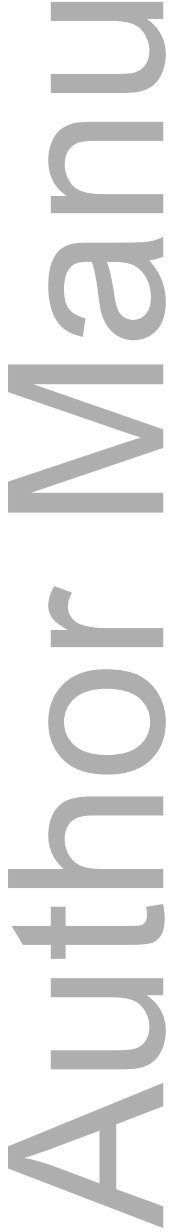

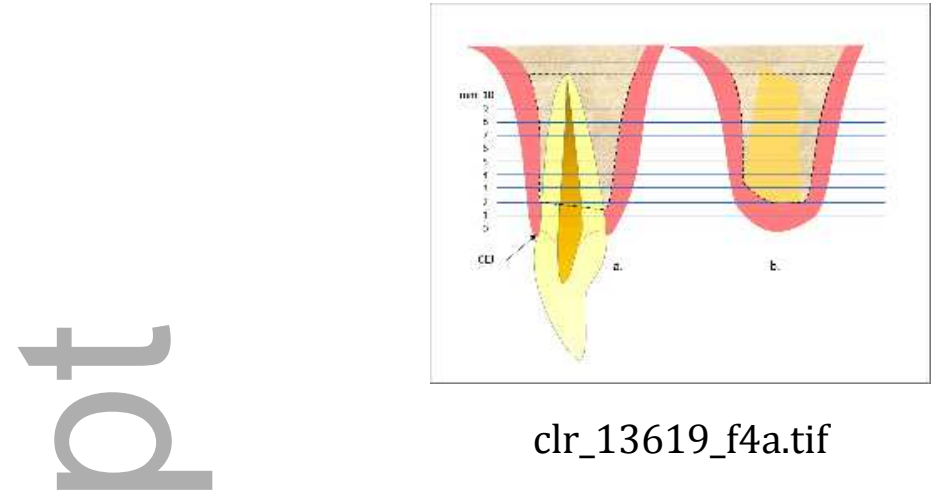

clr_13619_f4a.tif
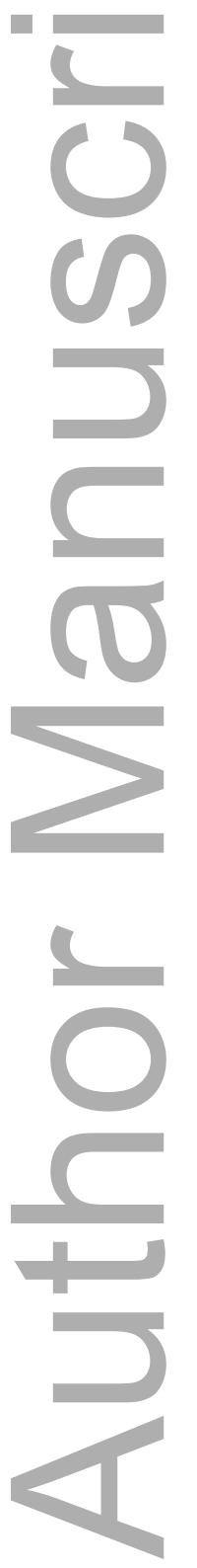

This article is protected by copyright. All rights reserved 


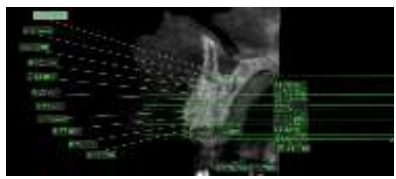

clr_13619_f4b.tif

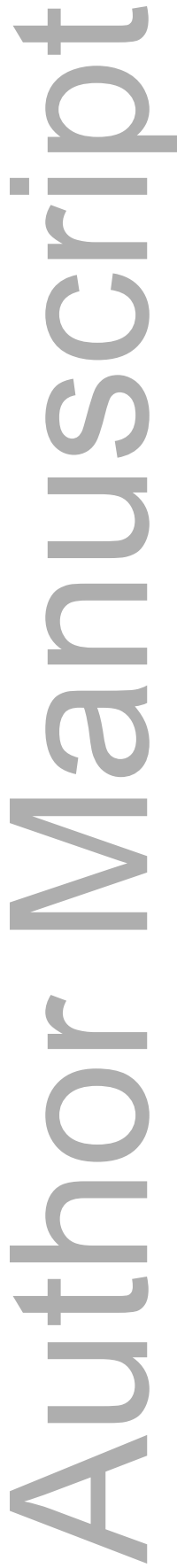




\section{University Library}

\section{- M M N E R VA A gateway to Melbourne's research publications}

Minerva Access is the Institutional Repository of The University of Melbourne

Author/s:

Chen, ST;Darby, I

Title:

Alveolar ridge preservation and early implant placement at maxillary central incisor sites: A prospective case series study

Date:

2020-06-18

Citation:

Chen, S. T. \& Darby, I. (2020). Alveolar ridge preservation and early implant placement at maxillary central incisor sites: A prospective case series study. CLINICAL ORAL IMPLANTS RESEARCH, 31 (9), pp.803-813. https://doi.org/10.1111/clr.13619.

Persistent Link:

http://hdl.handle.net/11343/275926 